\title{
Além das coisas e do imediato: cultura material, História imediata e ensino de História*
}

Marcos Silva**

Este artigo reflete sobre algumas possibilidades do Ensino de História com o universo da Cultura Material e a História Imediata. Ele evoca estas problemáticas nos Parâmetros Curriculares Nacionais - História e comenta dois ensaios da coleção "História da vida privada no Brasil”, que lhe são pertinentes.

Palavras-chave: Ensino de História - Cultura material - História imediata

Beyond Things and the Immediate. Material Culture, Immediate History and History Teaching

This article reflects on some possibilities in History Teaching concerning Material Culture and Immediate History universes. It evokes these problems in National Curriculum Parameters - History and comments two essays from the book collection "History of private life in Brazil" which are pertinent to the subject.

Keywords: History Teaching - Material culture - Immediate History

Au-delà des choses et de l'immédiat. Culture matérielle, histoire immédiate et enseignement d'histoire

Cet article est dédié à réfléchir sur quelques possibilités d'enseignement d'une histoire centrée autour de l'univers de la culture matérielle et de l'histoire immédiate. On évoque la façon comme ces problématiques apparaissent dans les Paramètres

\footnotetext{
"Artigo recebido em abril de 2006 e aprovado para publicação em junho de 2006.

** O autor é livre-docente em Metodologia da História pela FFLCH/USP e Professor na mesma instituição.E-mail: marcossilva.usp@uol.com.br.
} 
des Programmes Nationaux/Histoire et on commente aussi deux essais parus dans la collection "Histoire de la vie privée au Brésil".

Mots-clefs: Enseignement d'histoire - Culture matérielle - Histoire immédiate

O ensaísmo marxista, desde meados do século XIX, interpretou o Capitalismo visando a sua superação. Abordou o fazer-se material da experiência histórica (trabalho, alimentação, saúde) como uma de suas problemáticas centrais, articulada em relações de propriedade e poder, e considerou seu presente como História. ${ }^{1}$

$\mathrm{Na}$ passagem para a década de 30 do século XX, os debates que marcaram a criação da "Escola dos Annales" consolidaram um conceito universalizante de documento, abarcando vestígios de quaisquer fazeres humanos. ${ }^{2}$ Artefatos e o próprio corpo de homens e mulheres passaram a ser debatidos como fontes de pesquisa. $\mathrm{O}$ olhar dos historiadores foi também considerado em relação a experiências de seu presente, como se observa em artigos dedicados à Economia soviética, na etapa inicial da revista. Marc Bloch dedicou belas páginas à derrota francesa diante da Alemanha nazista e sobre outras questões do panorama internacional contemporâneo. ${ }^{3}$

Jacques Le Goff e Pierre Nora incluíram, na trilogia Faire de l'Histoire - continuadora da tradição da "Escola dos Annales" e manifesto inaugural da Nova História francesa ${ }^{4}$-, alguns ensaios que abordavam a historicidade a partir de experiências ligadas à materialidade da Cultura, como os textos de André Leroi-Gourhan, Henri Moniot, Alain Schnapp, André Burguière, Henri Zerner, Jacques Revel/Jean-Pierre Peter e Jean-Paul Aron. As reflexões metodológicas de Pierre Nora e Pierre Vilar, dentre outras, incidiram também sobre o imediato.

${ }^{1}$ Friedrich Engels, Situação da classe trabalhadora em Inglaterra, Porto, Afrontamento, 1975; Karl Marx, O Capital - Crítica da Economia Política (Tradução de Régis Barbosa e Flávio Kothe), São Paulo, Nova Cultural, 1988.

${ }^{2}$ Marc Bloch, Apologia da História ou O ofício do Historiador, Rio de Janeiro, Jorge Zahar, 2002; Lucien Febvre, Combates pela História, Lisboa, Presença, 1977.

${ }^{3}$ Marc Bloch, L' étrange défaite, Saint-Amand, Gallimard, 1990 (Folio Histoire - 27), $1^{\text {a }}$ ed. 1946.

${ }^{4}$ Jacques Le Goff e Pierre Nora (dirs.), História - Novos Problemas, Rio de Janeiro, Francisco Alves, 1976; Idem, História - Novas Abordagens. Tradução de Henrique Mesquita. Rio de Janeiro, Francisco Alves, 1976; Idem, História - Novos Objetos, Rio de Janeiro, Francisco Alves, 1976. 
Os debates da Nova História francesa retomaram tradições clássicas de pesquisa, representadas, no caso da Cultura Material, principalmente por Arqueologia e História da Arte, sem esquecer de História Local e História dos Costumes. Ao mesmo tempo, redirecionaram estas tradições: a Arqueologia tendia, antes, a ser encarada como adequada para as sociedades que legaram uma documentação escrita escassa, quando não eram ágrafas; ela priorizou, durante bom tempo, o objeto de cunho artístico; a História da Arte tendeu a ser isolada num plano de elevada espiritualidade da Cultura, à vida de grandes artistas e aos estilos considerados mais marcantes; e as Histórias Local e dos Costumes eram freqüentemente ligadas a setores menores da experiência. Num sentido similar, o trabalho da pesquisa histórica com sua contemporaneidade evidenciou o peso atribuído às relações entre passado e presente. ${ }^{5}$

Quando aqueles Historiadores rediscutiram esses universos, driblaram as hierarquias da erudição clássica e suas compartimentações. Tenderam, ainda, a deixar de lado projetos políticos explícitos, centrais no viés marxista, o que se consolidou com a queda do bloco soviético, nos anos 80 e 90 do século $\mathrm{XX}$, e o argumento ideológico do "fim da História". ${ }^{6}$ Apesar disto, muitas das questões debatidas pela tradição marxista continuaram a ser valorizadas e a História Social inglesa, de heterodoxa inspiração marxista, deu grande destaque à ação de grupos populares e ao seu cotidiano, a múltiplos suportes documentais e ao diálogo presente/passado. ${ }^{7}$

Os debates sobre Cultura Material e História Imediata tornaram-se referências clássicas, tanto para a Pesquisa acadêmica como para o Ensino fundamental e médio de História. Nos Parâmetros Curriculares Nacionais - História, tais vínculos foram evocados a partir da Nova História francesa e da História Social inglesa, mesmo que de forma ligeira, além de enfatizar pouco, ou sequer registrar, a importância de se problematizar o presente de que se fala historicamente. Correu-se o risco de reduzir o trabalho com Cultura Material ao arrolamento de diferentes artefatos, sem pensar sobre sua situação num mundo de homens e mulheres que se relacionam através de símbolos e poderes e se fazem por diferentes vias. O Imediato surgiu, por vezes, como

\footnotetext{
${ }_{5}^{5}$ Jean Lacouture, "A História Imediata”, Jacques Le Goff et al., A História, São Paulo, Martins Fontes, 1990, p. 215-240; Jacques Le Goff, "Passado/Presente”, Jacques Le Goff et al., História e Memória, Campinas, Editora UNICAMP, 2003, p. 207-233.

${ }^{6}$ Francis Fukuyama, O fim da História e o último homem, Rio de Janeiro, Rocco, 1992.

${ }^{7}$ Edward Thompson, Formação da classe operária inglesa, Rio de Janeiro, Paz e Terra, 1987; Raphael Samuel (org.), Historia populary Teoría socialista, Barcelona, Crítica, 1984.
} 
motivação pedagógica ou instância comparativa. Versão mais recente daquele documento oficial, dedicada ao Ensino médio, diminuiu tais deficiências, embora o Marxismo ainda seja abordado apenas a partir do século XX. ${ }^{8}$

No plano da História Imediata, muitos exemplos de Cultura Material se encontram na própria sala de aula e nos corredores e arredores da escola: corpos humanos, roupas, móveis, equipamentos esportivos, alimentos... Esta amostragem ainda é restrita, considerando-se a infinidade de outras experiências que lhe são contemporâneas. O Conhecimento Histórico ganha muito quando incorpora o imediato em seu universo, mas perde mais se ficar restrito a este mundo, como presente contínuo. Um de seus objetivos pode ser sair deste círculo vicioso, permitindo a compreensão de experiências sociais em diferentes temporalidades.

A Cultura Material, associada às outras problemáticas de conhecimento histórico, encontra múltiplos itens para reflexão em museus. Mesmo livros didáticos convencionais costumam apresentar fotografias e desenhos sobre alguns tópicos pertinentes à área, embora os explorem pouco. E o Patrimônio Histórico - edificado ou disperso em diferentes fazeres e saberes - contém inestimáveis elementos para a discussão daquele universo. A História Imediata, por sua vez, oferece um torrencial de possibilidades temáticas e documentais, a partir de seu trabalho com os processos históricos em andamento. Seu desafio maior é a identificação de agentes sociais e suportes documentais mais significativos para diferentes questões.

Discutirei aspectos da Cultura Material e da História Imediata a partir de dois ensaios editados numa série de livros do final do século XX, pensando sobre possíveis articulações entre eles e a Cultura Histórica do Ensino. A coleção História da vida privada no Brasil inclui alguns escritos que abordam o universo da produção material do cotidiano. Exemplo de ponta da Historiografia brasileira na passagem para o século XXI, a série é uma importante referência para o Ensino de História em diferentes graus, que dialoga com suas questões na definição de currículos. O passado mais recente (ou mesmo o Imediato dos Historiadores que a escreveram) se apresenta de forma mais palpável no último volume da série, embora questões de diferentes momentos possam servir de referência para refletir sobre práticas sociais do presente.

${ }^{8}$ Parâmetros Curriculares Nacionais / História, Terceiro e quarto ciclos do Ensino fundamental, Brasília, MEC/SEF, 1998; Parâmetros Curriculares Nacionais - PCN - Ensino médio, Brasília, MEC/SEMTEC, 2002. 
“A opulência na província da Bahia”, de Katia M. de Queirós Mattoso, ${ }^{9}$ articula a riqueza no século XIX com outras experiências sociais (o contraponto da pobreza, o aspecto fantasmagórico de algumas manifestações de suntuosidade). A autora indica como fonte de inspiração o livro A Bahia no século XVIII, ${ }^{10}$ seguindo-lhe os passos "com os instrumentos de análise de que dispomos", ${ }^{11}$ arrolando algumas das atividades que Salvador e seu porto dinamizavam na província, sujeitas às dificuldades do mercado internacional, do transporte e do abastecimento.

Mattoso salienta a importância de considerar os critérios de pobreza e riqueza próprios àquele momento, assinalando também que certo luxo escondia, às vezes, "miséria e sujeira". ${ }^{12}$ Para tanto, evoca a relação entre opulência e poder, partindo dos "altos escalões sociais", e destaca como, na Bahia, "a oposição portuguesa nobres/plebeus foi substituída pela oposição homens livres/escravos negros", ${ }^{13}$ proeminência dos brancos que a mestiçagem nuançou.

$\mathrm{Na}$ invocação de uma genealogia baiana, Katia identifica a opulência como meio de afirmar uma identidade nobre pelos notáveis, cujo prestígio decorria da posse de terras e da exibição do luxo. Realça, todavia, a flexibilidade dessa sociedade em relação às origens dos "candidatos à nobreza", ${ }^{14}$ que, segundo Vilhena, incluíam ricos mulatos, donde a autora retoma a caracterização dos senhores de engenho (feita por Stuart Schwartz ${ }^{15}$ ) como "aristocracia de riqueza e poder".

Katia Mattoso comenta limites na visão que viajantes estrangeiros tiveram dessa Bahia, mas assume a imagem de uma opulência "da Bahia inteira", ${ }^{16}$ desdobrando-se dos senhores para outras camadas de livres, marcando a vida dos escravos. Identifica alguma mobilidade no mundo escravo, expressa no

\footnotetext{
${ }^{9}$ Katia M. de Queirós Mattoso, “A opulência na província da Bahia”, Luiz Felipe de Alencastro (org.), Império: a corte e a modernidade nacional, São Paulo, Companhia das Letras, 1997, p. 143-179.

${ }^{10}$ Luís dos Santos Vilhena, A Bahia no século XVIII, Salvador, Itapuã, 1969.

${ }^{11}$ Katia M. de Queirós Mattoso, op. cit., p. 147.

${ }^{12}$ Ibid., p. 152.

${ }^{13}$ Ibid., p. 150.

${ }^{14}$ Ibid., p. 155.

${ }^{15}$ Stuart B. Schwartz, Segredos internos - Engenhos e escravos na sociedade colonial (1550/1835), São Paulo, Companhia das Letras, 1988.

${ }^{16}$ Kátia M. de Queirós Mattoso, op. cit., p. 156.
} 
desempenho de tarefas mais especializadas ou não, e uma onipresente e ilusória esperança de seus membros na obtenção de alforria, "Embora, ao que parece, as alforrias tenham sido proporcionalmente mais numerosas na Bahia do que em outras regiões do Brasil". ${ }^{17}$

A historiadora aponta a vaidade dos escravos de ricos, que se apresentavam bem vestidos e ornados com jóias e outros requintados adereços, e aproxima vantajosamente o estilo de vida dos escravos de ganho do de certos homens livres, concluindo pela fluidez entre os grupos sociais baianos da época. Ela assinala, também, uma dependência recíproca entre mulheres livres, que produziam diferentes mercadorias, e suas escravas, vendedoras de tais produtos nas ruas. ${ }^{18}$ São interessantes gradações, que contribuem para superar esquemas interpretativos rígidos, carecendo de alguma ênfase na preservação de um pólo dominante naqueles vínculos, com direito de propriedade e mando sobre o outro, e na construção de esboços de cidadania pelos mesmos diversificados escravos, muito antes da Abolição, através de sua própria presença em espaço público, dividindo experiências com homens livres. É possível pensar nos referidos adereços como atributos dos senhores daqueles escravos - as jóias e a escravaria pertenciam aos primeiros - à maneira das selas e dos freios que colocavam em seus cavalos, embora os escravos, por serem pessoas, recuperassem tais ornamentos numa identidade social que podia enfrentar seus proprietários.

Mattoso classifica fortunas baianas do século XIX, lembrando posses e atividades que as caracterizavam, das "muito pequenas" às "verdadeiras", identificando uma "elite da classe média", detentora de cerca de um terço das somas e das posses inventariadas. ${ }^{19}$ Ela qualifica um quarto dessas riquezas como pertencentes àquelas "pessoas que vivem de rendas", metade delas mulheres, importante evidência de poderes femininos na sociedade do período. ${ }^{20}$

Nesse universo, Katia faz algumas afirmações de caráter excessivamente genérico, como: "o empréstimo fácil caracteriza todas as classes sociais da Bahia"; "uma honestidade natural reina entre os baianos; ninguém quer

\footnotetext{
${ }^{17}$ Ibid., p. 157.

${ }^{18}$ Ibid., p. 164.

${ }^{19}$ Ibid., p. 162.

${ }^{20}$ Ibid., p. 163.
} 
morrer deixando dívidas" e "Os que tomam emprestado agem sempre de boafé". ${ }^{21}$ São observações de efeito alusivo, pouco claras em termos empíricos e conceituais. $\mathrm{O}$ acesso ao crédito para "todas as classes sociais da Bahia" pode sugerir uma absoluta isonomia social, rumo à impalpável utopia financeira, que não se realizou na Bahia - nem em lugar nenhum - do século XIX, e até hoje. A honestidade, de valor social, tende a se transformar em natureza provincial. A onipresença da boa-fé, por fim, tornaria desnecessárias leis e punições sobre seu avesso. Aqueles argumentos se confundem com tributos à baianidade, sem pontes para um universo historiográfico de explicação e demonstração. A própria Katia se encarrega de limitar tais excessos, quando declara que "A capacidade de fazer empréstimos, isto é, de encontrar facilidade na praça para tal, como a capacidade de poder emprestar, isto é, de dispor da liquidez necessária, são ambas sinais de opulência e sobretudo de prestígio" - não pertencem, portanto, a "todas as classes sociais da Bahia (...)".22

O exemplo da falência do rico negociante Cerqueira Lima, comentado pela historiadora, desempenha esta mesma função de retorno à empiria e à crítica.

Este próspero comerciante - detentor de fortuna muito expressiva, proprietário de moradia suntuosa, ornada com ricos adereços, servida por criadagem ricamente vestida, usando carruagens e outras evidências de grande riqueza, além de possuir muitos outros imóveis - morreu após ter sofrido sucessivas apreensões, pela Marinha inglesa, de navios carregados de escravos, e amargou uma espera de 15 anos, movendo um processo contra a Coroa britânica devido àqueles procedimentos. Em seu inventário, verificou-se um passivo de 100 mil contos de réis. Foram leiloados os objetos de luxo de sua moradia e arrendado o engenho de São Filipe à família Bettencourt Berenguer César, "da qual um dos membros se casou com a única filha legítima de Cerqueira Lima". ${ }^{23}$ Com perspicácia, Mattoso conclui sobre "a estratégia matrimonial que representa o casamento da filha de Cerqueira Lima ou a recusa dos credores a estender o crédito à viúva do negociante" que "a opulência na Bahia do século XIX (...) não se encontrava unicamente no luxo espalhado pela casa de Cerqueira Lima”. ${ }^{24}$ Aquela recusa também

${ }^{21}$ Ibid., p. 166.

${ }^{22}$ Ibid., p. 166.

${ }^{23}$ Ibid., p. 170.

${ }^{24}$ Ibid., p. 170. 
pode servir para identificar limites no acesso a crédito para uma endividada representante de abastadíssima elite!

Katia glosa comentários de Vilhena sobre senhoras baianas, que justificaram o trajar roupas leves pelo clima, salientando-lhes a fineza, o luxo, extensivo às escravas, o fato de serem fiéis nas amizades e o gosto pelas cerimônias sagradas. Estes temas servem de mote para a historiadora evocar o "viver como nobre", próprio das elites, mas igualmente identificável nas classes médias ${ }^{25}$ que explica pela presença da escravidão e pela "doçura na vida baiana", com baixo custo de vida, possibilidade de consumir supérfluos, acesso à casa própria para assalariados. ${ }^{26}$

A autora valoriza, em sua conclusão, uma "verdadeira riqueza", presente em paternais elites, "capazes de dar proteção e apoio", expressando-se n'“As redes de solidariedade, o desenvolvimento das instituições de crédito, das associações religiosas ou sociais, das sociedades de comerciantes ou de negociantes", referida "aos valores do coração e das relações entre os homens". ${ }^{27}$

Nesta passagem, a historiadora retoma um critério de verdade, com o risco de silenciar as mentiras ou falsificações como faces da experiência histórica. Vale pensar também sobre aquelas práticas como criadoras de dependências para o elo mais fraco da relação, questão que aparece no texto do mesmo volume "Senhores e subalternos no oeste paulista", de Robert W. Slenes. ${ }^{28}$ Junto com a tentativa senhorial de ampliar o domínio, os pactos também constituíam atos de poder das partes envolvidas.

A "verdadeira riqueza” será tão mais palpável historicamente quanto mais articulada a outras dimensões da vida privada baiana e brasileira do período, sem perder de vista o contraponto da miséria e o aspecto fantasmagórico de algumas maneiras de ser suntuoso - também as do coração!

O texto "Nem preto nem branco, muito pelo contrário: cor e raça na intimidade", de Lilia Schwarcz, ${ }^{29}$ apresenta um quadro de certa assimilação

\footnotetext{
${ }^{25}$ Ibid., p. 176.

${ }^{26}$ Ibid., p. 177.

${ }^{27}$ Ibid., p. 178-179.

${ }^{28}$ Robert W. Slenes, "Senhores e subalternos no oeste paulista”, Luiz Felipe de Alencastro (org.), Império: a corte e a modernidade nacional, op. cit., p. 236.

${ }^{29}$ Lilia Moritz Schwarcz, "Nem preto nem branco, muito pelo contrário: cor e raça na intimidade", Idem (org.), Contrastes da intimidade contemporânea, São Paulo, Companhia das Letras, 1998, p. 173-243 (História da vida privada no Brasil - 4).
} 
cultural no Brasil, mesclada à exclusão social, de contingentes populacionais definidos por cor e raça - particularmente, negros.

$\mathrm{Na}$ abertura do ensaio, figura o tema do tornar-se branco, através de conto infantil brasileiro, publicado originalmente em 1912: uma princesa nascera negra devido à má formulação de pedido que a branca rainha - sua mãe e até então sem filhos - fizera à rainha das fadas: "Oh! Como eu gostaria de ter uma filha, mesmo que fosse escura como a noite que reina lá fora". No final da narrativa, depois de sofrimentos e dificuldades, Negrina, aquela personagem, se transforma em alva e feliz esposa do Príncipe Diamante - a felicidade incolor e preciosa...

Este episódio literário foi situado nos quadros do projeto racista de branqueamento da população nacional, ideologia disseminada na passagem para o século XX, de acordo com a qual "quanto mais branco melhor", ${ }^{30}$ malgrado alguns argumentos da época, contrários à miscigenação, vista como degenerescência. Importantes nomes do ensaísmo social brasileiro aparecem entre estes ideólogos racistas: Sylvio Romero, Euclides da Cunha, Roquette Pinto e Nina Rodrigues. O branqueamento é interpretado por Schwarcz como vontade de ver índios e negros desaparecerem da população nacional, conforme projeção de Roquette Pinto para o ano 2012. ${ }^{31}$ A autora não mencionou alguns pioneiros críticos destes escritores e do racismo no mesmo período, como o médico, educador e ensaísta Manoel Bomfim e o romancista e cronista Lima Barreto. ${ }^{32}$ Também não foram realçadas conquistas interpretativas mesmo em alguns daqueles outros ensaístas mais vinculados às teorias raciais, como Romero e Cunha. ${ }^{33}$

O núcleo principal debatido no texto de Schwarcz é a transformação das abordagens sobre raça e mestiçagem no país, a partir dos anos 30 do século $\mathrm{XX}$, e já esboçada entre os primeiros modernistas: a condição mestiça vista como ideal no plano da cultura, alçada à dupla identidade de mito de estado e tema antropológico, numa estetização da democracia racial; raça e racismo

\footnotetext{
${ }^{30}$ Ibid., p. 136.

${ }^{31}$ Apud ibid., p. 177.

32 Manoel Bomfim, América Latina - Males de origem, Rio de Janeiro, Topbooks, $1998\left(1^{\mathrm{a}}\right.$ ed.: 1905); Afonso Henriques de Lima Barreto, Triste fim de Policarpo Quaresma, São Paulo, Brasiliense, 1976 (Obras Completas - II), $1^{\text {a }}$ ed. 1915.

${ }^{33}$ Sylvio Romero, Contos populares do Brasil, Rio de Janeiro, José Olympio, 1954 (Documentos brasileiros - 75B), $1^{\text {a }}$ ed. 1883; Euclides da Cunha, Os Sertões, edição crítica por Walnice Nogueira Galvão, São Paulo, Ática, 2000, 1ª ed. 1902.
} 
virando quase tabus; o preconceito projetado como problema do passado; o deslocamento do racismo para os espaços da intimidade; as condições de vida de negros, mestiços e índios permanecendo como fantasmagorias e encobertas pela idealização daquela suposta democracia.

Schwarcz destacou que a escravidão "legitimou a inferioridade e, enquanto durou, inibiu qualquer discussão sobre cidadania. (...) o trabalho limitou-se exclusivamente aos escravos". ${ }^{34}$ Vale a pena lembrar que, mesmo no período colonial, determinadas tarefas foram reservadas ao trabalhador assalariado - caso de atividades especializadas no engenho. ${ }^{35}$ Argumentos de legitimação da inferioridade são muito significativos para o debate, mas houve nuances da cidadania brasileira em construção, no século XIX, que passaram pela presença escrava na cena pública - da Inconfidência Baiana, no final do século anterior, à construção de redes de comunicação entre escravos, em cidades e áreas rurais, e à definição de sentimentos de honra e privacidade por eles. ${ }^{36} \mathrm{~A}$ associação entre as teorias racistas e a República, no Brasil, não deve fazer esquecer que tais argumentos se faziam presentes noutras partes do mundo à época (nos Estados Unidos, por exemplo), e mesmo depois (sul dos Estados Unidos, até a década de 60 do século XX, e África do Sul, ainda mais), assumindo contornos específicos em cada historicidade nacional.

Aquelas mudanças dos anos 1930 abrangeram a criação oficial de um "Dia da raça" (1938), sem se restringirem ao Estado Novo nem às instituições brasileiras, como se observa no endosso da UNESCO a projeto de pesquisa sobre a harmonia racial no país, em 1951 (pós-guerra, com a trágica lembrança do Holocausto), e na difusão internacional da Literatura de Jorge Amado e da Sociologia de Gilberto Freyre.

As críticas ao mito da democracia racial, atentas às desigualdades sociais e à identidade de classe, foram indicadas por Schwarcz nos estudos sociológicos de Luiz Costa Pinto, Roger Bastide e Florestan Fernandes (mesmo nos quadros daquele projeto da UNESCO), depois desdobrados nos trabalhos de Octavio Ianni e Fernando Henrique Cardoso. Nas obras de Fernandes, Lilia destacou a identificação de um racismo brasileiro "de caráter privado e pouco

\footnotetext{
${ }^{34}$ Lilia Moritz Schwarcz, op.cit., p. 185.

${ }^{35}$ Antonil, Cultura e opulência do Brasil, Belo Horizonte/São Paulo: Itatiaia/EDUSP, 1982 (1ª ed. 1711).

${ }^{36}$ José Carlos Barreiro, Imaginário e viajantes no Brasil do século XIX - Cultura e cotidiano, tradição e resistência, São Paulo, Editora UNESP, 2002; Robert W. Slenes, op. cit.
} 
formalizado", que engloba a defesa do branqueamento como ideal, a imagem do "negro de alma branca" e a hierarquização a partir de critérios de cor. ${ }^{37}$ Salientou, ainda, que movimentos negros, a partir dos anos 70 do século XX, ampliaram tais críticas.

O caráter não-oficial do preconceito, no Brasil, preservou a eclosão de racismos, em nome de Ciências ou Costumes. O texto cita, dentre outras evidências desta situação, pesquisa de Sérgio Adorno, sobre práticas penais - os negros sendo identificados, em processos, como mais perigosos, os réus "embranquecendo" ou "escurecendo", nos registros, de acordo com inocência ou culpabilidade.

A autora expôs um quadro de manutenção de hierarquias raciais através deste preconceito não-oficial, situado na esfera da intimidade. Apontou condições sociais inferiores da população brasileira negra e mestiça, com menor acesso à Educação e a saneamento público, taxas mais altas de mortalidade infantil, menor expectativa de vida, casamento mais tardio e maiores percentuais de celibato masculino. Mesmo a legislação anti-racista (Lei Afonso Arinos) foi identificada como pouco eficaz, situação reiterada na Constituição de 1988, que considerou discriminatórios apenas atos públicos. ${ }^{38}$

Comentando padrões de matrimônio no Brasil, Schwarcz lembra que a endogamia é maior entre brancos e as mulheres desta cor têm maiores vantagens. Evoca, ainda, a expressão "raça social” para designar identificações derivadas de condições socioeconômicas, caso de uma mulher, definida como branca pelo agente de recenseamento e que, caracterizando-se como negra ou parda, ouviu: "Mas a senhora não é professora da USP?". ${ }^{39}$

Os textos de Mattoso e Schwarcz trabalham dimensões da Cultura Material e da História Imediata presentes em sala de aula: os corpos dos seres humanos, em sua multiplicidade de cores, tipos de cabelos, lábios, narizes e outros atributos físicos, traduzidos em valores sociais; a associação entre estes seres humanos e experiências históricas de seus semelhantes físicos e/ou culturais; diferentes aproximações, em múltiplas experiências históricas, entre cor, raça, direitos e poderes.

A eventual ausência desta pluralidade em algumas escolas (os estabelecimentos de elite, talvez mais brancos, com tonalidades amarelas, em que

${ }^{37}$ Lilia Moritz Schwarcz, op.cit., p. 205.

${ }^{38}$ Ibid., p. 213.

${ }^{39}$ Apud ibid., p. 231. 
há descendentes dos imigrantes asiáticos) também constitui elemento de interesse para discutir tal faceta de Cultura Material e História Imediata e tem por contrapartida a maioria negra e mulata em filmes que falam de pobreza e violência social, como Cidade de Deus, de Fernando Meirelles, ou as associações entre cor e criminalidade, dispersas em noticiário jornalístico e comentadas criticamente por Schwarcz, a partir de pesquisa sobre processos penais. Aquela diversidade ou uma correspondente homogeneidade de cores humanas são problemas de conhecimento, bastante acessíveis aos alunos de diferentes graus de ensino, nos planos de Cultura Material e História Imediata.

Que fazer para ir além da História Imediata, sem a perder? E como integrar neste percurso de Conhecimento Histórico as evidências de Cultura Material que ultrapassam os corpos humanos ali presentes?

Não pretendo responder a estas questões com alguma saída universal. O melhor Ensino de História ocorre em diálogos entre o Professor, a escola em que ele atua, o público com quem ele trabalha e as instituições especializadas deste campo de Conhecimento. A escola do Ensino fundamental e a do médio são espaço multidisciplinar de disputa entre diferentes projetos de Conhecimento e concepções de Educação. Não se trata, portanto, de supor que todos os professores de História optarão pelo universo metodológico aqui abordado nem enfrentarão as consequiências políticas derivadas de algumas das opções aqui feitas.

Considerarei, portanto, apenas uma situação hipotética do professor que faz um percurso de diálogo intradisciplinar (depois, também, multidisciplinar) e de escolha pedagógica e política. Não espero uma resposta em comum de todos para estas situações, que anularia os atos de diálogo e escolha. Partindo de minha experiência na formação de professores e de contatos com a prática destes profissionais, indicarei algumas possibilidades de trabalho neste universo de conhecimento.

Um primeiro passo na discussão é identificar a História Imediata como uma necessidade do Conhecimento Histórico, em geral, e de seu Ensino, em particular. Sem ela, a noção de tempo histórico se restringe ao puro passado e à origem, mitos tão bem criticados por Marc Bloch. ${ }^{40}$ Sem ela, a História ensinada se configura como espetáculo para alunos que não fazem parte da cena - risco epistemológico e político, que reforça argumentos da dominação social: a História se transforma em privilégio de alguns personagens e acon-

${ }^{40}$ Marc Bloch, op. cit. 
tecimentos, os demais são platéia ou cenário. Os limites da História Imediata (infinitude de informações e agentes, possibilidades em aberto) contribuem para entender outros momentos como dotados de situações paralelas, desmontando a imagem daquele "espetáculo" dos passados como inevitabilidade. E a História Imediata se reporta a problemas clássicos de Conhecimento Histórico, desde os pais fundadores gregos: Heródoto e Tucídides não escreviam sobre seu tempo presente? ${ }^{41}$

Justificada a História Imediata, vem a urgência de seu além: ela não existe sem as experiências pretéritas, ela se abre sempre para possibilidades mais ou menos palpáveis, sem descartar o acaso - e não para um vazio. Este estar entre o passado e o futuro ${ }^{42}$ realça a necessidade teórica, pedagógica e política de se pensar sobre a História Imediata, sem nela permanecer, e expressa um projeto de Conhecimento Histórico auto-reflexivo, que pretende refletir sobre seu processo e a sociedade em que ocorre, sem assumir um mero papel legitimador daquele mundo e de si mesmo.

Para ir além da História Imediata, o trabalho do professor com as instituições especializadas de sua área de conhecimento (Historiografia, universidades, museus, bibliotecas, arquivos, etc.) é necessário. Evidentemente, estas unidades de pesquisa e divulgação do saber histórico não oferecem respostas prontas. Tomando os textos de Mattoso e Schwarcz como referências para este percurso, à guisa de exemplo, levantarei alguns tópicos para pensar sobre o diálogo metodológico com aqueles níveis da análise histórica.

Mattoso realça a complexidade das relações entre senhores e escravos, citando o refinamento das roupas e dos adereços de alguns cativos, que chegavam a incluir jóias de alto valor. Estes ornamentos caros foram representados por artistas que estiveram no Brasil na época. Não costumam ser encontrados em museus e instituições similares, na condição de objetos de alto preço, usados pelo escravo X ou pela escrava Y. Em contrapartida, jóias e roupas de luxo, que pertenceram a pessoas ricas da mesma época (a baronesa $\mathrm{K}$, o ministro L - algumas delas proprietárias de escravos semelhantes àqueles), fazem parte do acervo de importantes museus históricos brasileiros. Por que esta diferença de destino?

${ }^{41}$ Heródoto. História, Brasília, EdUnB, 1985; Tucídides, História da Guerra do Peloponeso, Brasília, EdUnB, 1987.

${ }^{42}$ Hannah Arendt, Entre o passado e o futuro, São Paulo, Perspectiva, 2000. 
Uma primeira questão diz respeito à própria relação de propriedade: as jóias não pertenciam aos escravos, eles mesmos eram propriedades de outras pessoas. Jóias e roupas que chegaram aos museus, freqüentemente, foram doadas por herdeiros de seus proprietários originais, que demonstraram espírito público (poderiam ganhar muito dinheiro se as vendessem no mercado de antigüidades) e vontade de ter reconhecida uma imagem de origem nobre (não é qualquer um que possui objetos tão preciosos, herança de família, e pode abrir mão de seu valor comercial para ser nobilitado no acervo de uma instituição respeitável: é melhor que árvore genealógica duvidosa...). Houve casos de escravos que compraram a alforria e enriqueceram. É possível que alguns de seus pertences cheguem a museus, como objetos de pessoas livres e ricas.

Apesar disto, o comentário de Mattoso sobre o aspecto luxuoso de alguns escravos merece atenção, embora não se possa contar com as evidências materiais diretas de jóias e roupas caras por eles usadas. Mesmo sem possuírem aqueles objetos nem poderem legá-los como herança para seus descendentes, os escravos deviam sentir prazer em seu uso, índice de uma auto-estima e do convívio com a beleza. Nos Maracatus, cortes negras se apresentavam e apresentam, em cortejo festivo, com roupas que remetem à suntuosidade e à riqueza. ${ }^{43}$ Uma exposição itinerante, organizada pelo Ministério da Cultura, nos anos 90 do século $\mathrm{XX}$, reuniu materiais de vários museus brasileiros, sob o título "Tesouros do Patrimônio". Uma das salas agrupou um vestido de dama da corte de Pedro II, um vestido de princesa do Maracatu, uma rica bandeja de prata e um instrumento de prender e torturar escravos. Esta seqüência, aparentemente desconexa, lembra-nos relações de natureza material (não haveria vestido de dama e bandeja sem os escravos) e de memória cultural (escravos podiam ver-se como pessoas belas e dignas de ornamentos que evocavam o direito ao esplendor, e seus descendentes biológicos e culturais podem preservar esta visão).

No texto de Schwarcz, os comentários sobre a mescla brasileira entre preconceitos contra negros e mestiços e a idealização cultural dos negros e dos mestiços como síntese da nação podem contribuir para o debate recente sobre cotas para afro-descendentes (e, em menor escala, indígenas) nas universidades.

${ }^{43}$ Luís da Câmara Cascudo, Dicionário do Folclore brasileiro, São Paulo, Global, 2001, p. 361362 (1 $1^{\text {a }}$ ed., 1956). 
Esta discussão possui um grande mérito: reconhecer que existe diferença entre descendentes de europeus, africanos e indígenas no acesso à universidade brasileira. Se a questão for discutida apenas no nível "racial", corre-se o risco de repor perspectivas preconceituosas (chegou-se a falar em "provas científicas" de ser negro!) e de esquecer que amplas parcelas da população euro-descendente também estão excluídas da universidade brasileira - e do acesso adequado à saúde, à moradia, à alimentação...

Silencia-se a existência de uma estrutura de classes que não atinge os afro-descendentes (e, em menor escala, os próprios indígenas) apenas pela exclusão. Não é descabido falar numa classe média negra, já atendida por produtos e serviços (artigos para maquiagem, revistas, etc.) e que se fazia presente na universidade mesmo antes dos debates sobre cotas. Omitida esta discussão sobre estrutura de classes, perde-se de vista que as cotas repõem práticas excludentes: jovens afro-descendentes, de classe média, até podem beneficiar-se daquela política, classificando-se para bons cursos públicos ou privados, enquanto seus semelhantes mais pobres continuarão excluídos daquele espaço ou terão que se contentar com escolas privadas de má qualidade.

Precisamos, então, de Cultura Material e História Imediata no Ensino de História para crianças e adolescentes? A resposta é afirmativa, se ousarmos pensar num Ensino de História que, problematizando o mundo, se problematiza.

Mas é claro que este não é o único caminho. 